\title{
TRANSFORMAÇÃO CURRICULAR EM UMA ESCOLA DE EDUCAÇÃO INFANTIL NO PIAUÍ PELO VIÉS DA PESQUISA E FORMAÇÃO DOCENTE
}

\author{
CURRICULUM TRANSFORMATION IN A CHILD EDUCATION SCHOOL IN PIAUÍ BY \\ THE RESEARCH AND TEACHER TRAINING
}

\section{TRANSFORMACIÓN CURRICULAR EN UNA ESCUELA DE EDUCACIÓN INFANTIL EN PIAUÍ POR LA INVESTIGACIÓN Y LA FORMACIÓN DE PROFESORES}

\begin{abstract}
RESUMO
Este artigo, de modo geral, apresenta recorte de uma pesquisa de doutorado que discute, centralmente, a reorganização do currículo de uma escola de Educação Infantil a partir da implementação de um projeto de intervenção organizado por Atividades Sociais. Tal reorganização foi possível mediante intenso processo de formação contínua na escola envolvendo pesquisadora, gestora e professoras. Especialmente, o texto propõe discutir a formação docente de professores de Educação Infantil numa perspectiva que foge dos moldes clássicos de formação e caminha na direção de uma nova perspectiva voltada para reflexão-crítica que articule teoriaprática. Para tanto é apresentado excertos reveladores do processo de transformação que o currículo da escola sofreu com as aprendizagens favorecidas no processo de formação. A discussão se assenta na pesquisa crítica de colaboração-PCCol e no projeto intervencionista-revolucionário de Vigotski. A materialidade da investigação foi produzida a partir de encontros de formação em uma escola de Educação Infantil localizada na cidade de Parnaíba-PI. No caso, três excertos são apresentados e analisados com base na perspectiva argumentativa da linguagem que dá indícios reveladores da transformação da prática, via formação. O entrelaçamento da formação contínua e a intervenção de um projeto com base em Atividades Sociais na escola propiciou cenários para desenvolvimento de uma prática docente articulada com a teoria e consequentemente a transformação do currículo escolar.
\end{abstract}

Fabricia Pereira Teles

Universidade Estadual do Piauí / CNPq

E-mail: fabriciateles@phb.uespi.br

PALAVRAS-CHAVE: Educação infantil. Formação contínua. Reorganização curricular.

\section{ABSTRACT}

This article, in general, presents a clipping of a doctoral research that discusses, centrally, the reorganization of the curriculum of a preschool based on the implementation of an intervention project organized by Social Activities. Such reorganization was possible through an intense process of continuous formation in the school involving the researcher, the principal and the teachers. In particular, the text proposes to discuss the teacher training of preschool teachers in a perspective that is beyond the classical molds of training and moves towards a new perspective focused on critical reflection that articulates theory and practice. For that, revealing excerpts of the transformation process that the school curriculum suffered from the learning favored in the formation process are presented. The discussion is based on the principles of critical collaboration research and on Vigotski's interventionist-revolutionary project. The materiality of the research was produced at training meetings in a preschool located in the city of Parnaiba-PI. In this case, three excerpts are presented and analyzed based on the argumentative perspective of language that indicates the transformation of the practice through training. The intertwining of continuing training and the school intervention project based on Social Activities provided scenarios for the development of a teaching practice articulated with theory and consequently the transformation of the school curriculum. 


\section{RESUMEN}

Este artículo, en general, presenta un recorte de una investigación doctoral que discute, de manera central, la reorganización del plan de estudios de un preescolar basado en la implementación de un proyecto de intervención organizado por Actividades Sociales. Dicha reorganización fue posible a través de un proceso intenso de formación continua en la escuela que involucró a investigadores, gerentes y maestros. En particular, el texto propone discutir la formación docente de los maestros de preescolar en una perspectiva que está más allá de los moldes clásicos de formación y avanza hacia una nueva perspectiva centrada en la reflexión crítica que articula la teoría y la práctica. Para eso, presentamos extractos reveladores del proceso de transformación que el currículo escolar sufrió del aprendizaje favorecido en el proceso de formación. La discusión se basa en la investigación de colaboración crítica de PCCol y el proyecto revolucionario intervencionista de Vigotski. La materialidad de la investigación se produjo a partir de reuniones de capacitación en un preescolar ubicado en la ciudad de Parnaiba-PI. En este caso, se presentan y analizan tres extractos basados en la perspectiva argumentativa del lenguaje que da indicaciones reveladoras de la transformación de la práctica, a través de la formación. El entrelazamiento de la educación continua y la intervención de un proyecto basado en actividades sociales en la escuela proporcionaron escenarios para el desarrollo de una práctica docente articulada con la teoría y, en consecuencia, la transformación del currículo escolar.

PALABRAS CLAVE: Educación de la primera infancia. Formación contínua. Reorganización curricular

\section{INTRODUÇÃO}

Este artigo, de modo geral, apresenta recorte de uma pesquisa de doutorado defendida em 2018 - junto ao Programa de Pós-graduação em Linguística Aplicada-PUC/SP - que discute, centralmente, o currículo de uma escola de Educação Infantil. Tal pesquisa conduziu a implementação de um projeto de intervenção escolar organizado por Atividades Sociais ${ }^{1}$ (LIBERALI, 2009), denominado "Ir à lanchonete". Destaca-se que o organizador curricular do projeto tem o conceito de brincar (VIGOTSKI, 2007) um de seus aportes principais. A implementação do projeto e reorganização curricular aconteceu após intenso processo de formação contínua na escola envolvendo pesquisadora, gestora e professoras.

Especialmente, o texto propõe discutir a formação docente de professores de Educação Infantil numa perspectiva que foge dos moldes clássicos de formação, centrado nos cursos técnicos ou aligeirados, e caminha na direção de uma perspectiva apoiada na reflexão-crítica que articule a relação teoria-prática na escola, no sentido de harmonizar o descompasso da formação contínua.

Para tanto, a tessitura deste texto, primeiramente, trata sobre a discussão teórica que critica modelos de formação para Educação Infantil, centrado em técnicas, em detrimento da sustentação teoria-prática. Aborda, na sequência, aspectos metodológicos da pesquisa explicitando a formação na escola dentro do quadro da pesquisa crítica de colaboração-PCCol (MAGALHÃES, 2014) e no projeto intervencionista-revolucionário de Vigotski (NEWMAN E HOLZMAN, 2014). No mesmo item, é apresentado a escola e alguns dos procedimentos 
adotados para produção dos dados da investigação. Também, três excertos são apresentados e analisados com base na perspectiva argumentativa da linguagem (LIBERALI, 2013).

Por fim, conclui-se o artigo afirmando que o entrelaçamento da pesquisa-formação e a intervenção de um projeto com base em Atividades Sociais (LIBERALI, 2009) na escola, propiciou cenários para desenvolvimento de uma prática docente articulada com a teoria, bem como, a transformação do currículo escolar na Educação Infantil.

\section{FORMAÇÃO DE PROFESSORES E ARTICULAÇÃO TEORIA-PRÁTICA}

De acordo com o Censo Escolar 2016, nas creches brasileiras atuam 260,3 mil professores, dos quais $61 \%$ deles possuem escolaridade superior com licenciatura e $20 \%$ têm curso normal/magistério, $6,2 \%$ com nível médio completo e $0,5 \%$ com nível fundamental completo. Na pré-escola, esse número salta para 311.406 docentes. Dentre esses docentes, $62,6 \%$ possuem escolaridade superior com licenciatura e 18,5\% têm curso normal/magistério, $5,7 \%$ com nível médio completo e $0,3 \%$ com nível fundamental completo. Nesses dados, o que nos interessa é que o maior percentual da formação dos professores da Educação Infantil brasileira está acima de $60 \%$ na licenciatura, mais frequentemente, na licenciatura em Pedagogia.

A formação docente, em qualquer licenciatura, é aspecto fundamental para transformação do que se espera encontrar na escola. Nesse entender, no campo curricular, as mudanças precisam acontecer como resultado de um processo crítico-reflexivo de amplo debate. Seja ele na esfera federal, estadual, nas redes de ensino municipal, mas sobretudo, no âmbito e contexto escolar, local em que, efetivamente, o professor como intelectual transformador se liberta das amarras impostas por um sistema burocrático e técnico (GIROUX, 1997).

Entretanto, como aponta Kramer (2002), em se tratando de Educação Infantil, o assunto torna-se extremamente desafiador, visto que, embora tenha ocorrido um crescente aumento na qualificação profissional, após as décadas de 80, elas aconteceram carregadas de polêmicas. Por exemplo, para a pesquisadora citada, uma questão problemática na formação do profissional da educação infantil foi a valorização desenfreada da racionalidade tecnocrática e instrumental que "treinou" os professores para executarem uma porção de técnicas focadas na repetição de comportamentos desejados e controle absoluto das crianças (e também dos professores) com ênfase a uma perspectiva behaviorista. 


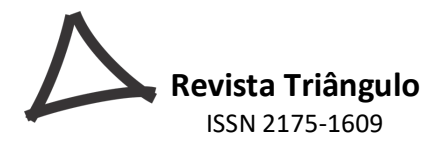

Nessa direção, para Giroux (1997, p. 159), “em vez de aprenderem a refletir sobre os princípios que estruturam a vida e a prática em sala de aula, os futuros professores aprendem metodologias que parecem negar a própria necessidade do pensamento crítico", o que significa um paradoxo em se tratando do professor um intelectual.

Para Kramer (2002), outra questão problemática foi a difusão equivocada feita por universidade, de políticas educacionais e reformas curriculares, ao se propor aos professores currículos de licenciaturas com um conjunto de informações distorcidas e genéricas "muito distante da consciência teórica da epistemologia genética ou da perspectiva sócio histórica do conhecimento. Este problema é constatado ainda hoje nas propostas pedagógicas atuais" (KRAMER, 2002, p. 4-5).

Em consonância com as ideias dos autores referenciados e o que pondera Kishimoto (1994) sobre currículo, para se evitar tal realidade, no lugar de se impor, verticalmente, uma proposta de ensino, é preciso que, em contexto de formação continuada, professores e educadores reflitam com sua comunidade escolar sobre o tipo de instituição que objetivam constituir para a formação das crianças, sobre o contexto em que objetivam desenvolver a proposta pedagógica, e sobre, quais os aspectos ideológicos, filosóficos, sociológicos, culturais, políticos, econômicos e psicológicos estão envolvidos na proposta produzida. Enfim, refletir sobre que homem e sociedade se espera no futuro, frente às crianças nas escolas que atuam.

Contudo, a origem da Educação Infantil desvinculada da escola, a tradicional concepção assistencialista de currículo oferecida às crianças e o histórico das funções higienistas do perfil profissional levaram à formação docente associada a ações, explicitamente, práticas, sem qualquer exigência mais aprofundada sobre bases teóricas que possibilitassem entender como a criança se desenvolve e se constitui socialmente nos contextos escolares de Educação Infantil e como se apropria de repertórios necessários à sua ação nos contextos escolares e no mundo.

Segundo Raupp (2012), a perspectiva que coloca a instituição "escola" de Ensino Fundamental como espaço privilegiado para o domínio de conhecimentos científicos e a instituição de "Educação Infantil" (centros, creches, pré-escolas, etc.) apenas com fins complementares à família propõe como secundária a formação desse profissional.

Nessa tradição, o professor tem função limitada à observação, à organização do espaço físico, ao acompanhamento dos interesses das crianças, à higienização. Todos esses aspectos são importantes, porém são insuficientes para definir a real finalidade do professor na educação infantil (OLIVEIRA, 2014). 


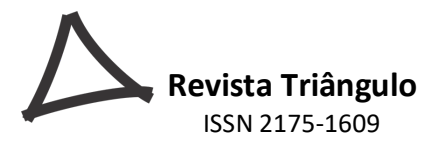

Essa perspectiva marca uma organização curricular para Educação Infantil em que o professor afasta-se, literalmente, de qualquer deliberação e reflexão crítica sobre o processo de aprendizagem e produção de conhecimento, para se deter no papel de mero executor de rotinas na escola (mero cuidador, - sem qualquer distinção de outro profissional sem formação específica), bem distante de seu real papel que requer uma ativa participação na produção de um currículo adequado ao contexto cultural e social em que trabalha. É o estigma da polarização entre prática versus teoria.

Rech (2017), com base em Adorno, salienta que a versão pragmática foi tomada na modernidade como o modelo para se alcançar o conhecimento. Isso, no caso da formação de professores, em geral, levou à perda da consciência da profissão. Em uma teoria de práxis, prática e teoria não estão isoladas uma da outra, mas formam uma unidade. Em consequência, a teoria foi destruída, mediante o primado da razão prática, impulsionadora de umas práxis arbitrária e irracional. Em crítica a concepção polarizante, Adorno (1995, p.24) esclarece:

Pensar é um agir, teoria é uma forma de práxis; somente a ideologia da pureza do pensamento mistifica este ponto. O pensar tem um duplo caráter: é imanentemente determinado e é estringente e obrigatório em si mesmo, mas, ao mesmo tempo, é um modo de comportamento irrecusavelmente real em meio à realidade. Na medida em que o sujeito, a substância pensante dos filósofos, é objeto, na medida em que incide no objeto, nessa medida, ele é, de antemão, também prático.

Na década de 1990, a expansão da literatura sobre a Educação Infantil, em âmbito nacional e internacional articuladas à eminência de uma política de formação profissional, provoca a constituição de uma especificidade para área que requer exigência profissional.

Em cumprimento às exigências da LDB 9394/96, estruturas de formação para o professor de Educação Infantil foram criadas para atender a essa demanda que crescia. Mas, como aponta Raupp (2012), embora as políticas educacionais defendessem uma compreensão da real necessidade de se formar professores para atuarem na Educação Infantil, em geral, essas formações aconteciam de maneira aligeiradas e esvaziadas de teoria. De fato, uma grande parcela das formações (inicial e contínua) oferecidas aos professores de Educação Infantil, estiveram pautadas em uma epistemologia da prática, focada em desafios e tarefas de cunho cotidiano, que pouco exigia desses profissionais o desenvolvimento e aprofundamento de conhecimentos de cunho teórico, distanciando-se de reflexões filosóficas, sociológicas e mesmo psicológicas que ultrapassassem as grades do cotidiano das creches e pré-escolas. 
Segundo Raupp (2012), nas creches e pré-escolas, as formações sustentadas por uma epistemologia da prática e ontologia empírica aparecem nas abordagens que defendem a formação reflexiva na perspectiva do "aprender a aprender", o "professor pesquisador" e o “desenvolvimento de competências".

Para a autora, isso acontece em razão de premissas de um discurso banalizado que supervaloriza os saberes da experiência em detrimento dos conhecimentos teóricos como se fosse possível afastar a prática da teoria ou a teoria da prática. No corpus das pesquisas analisadas pela pesquisadora, quando o assunto é formação de professores de Educação Infantil, valorizam-se suas histórias de vida, suas narrativas, as trocas em contexto escolar, a construção de competências a partir da prática. Quase nada se encontra na formação de conhecimentos emancipatórios, transgressivos ou que apontem reflexões críticas que provoquem o avanço de concepções e ideias para além da prática trancafiada nos muros da escola.

Como essa estudiosa aponta, falar das histórias de vida e das produções de conhecimento na escola não é totalmente negativo na formação de professores, a questão é que não se deve limitar a esses aspectos. Da mesma forma, a supervalorização do conhecimento teórico, o "saber o quê", também não desencadeia um processo de reflexão crítica que leve à superação de práticas sociais escravizantes, tradicionalmente valorizadas nas universidades, cursos de formação continuada e mesmo nas discussões nas escolas.

Autores como Sacristán e Pérez Gomez (1998) e Magalhães (2014) defendem que somente ao compreender o que se faz é possível superar uma prática pedagógica reprodutora de hábitos e pressupostos dados verticalmente. Para isso, é preciso conhecer a realidade herdada, a realidade que se tem, discutir as propostas de ensino que se têm e as que estão sendo propostas e suas possíveis consequências para caminhar em direção de um trabalho docente ético e responsável.

Segundo a Resolução de $\mathrm{n}^{\circ} 2$ do CNE/2015, que reza sobre as Diretrizes Curriculares Nacionais para a Formação Inicial em Nivel Superior e Formação Continuada, em seu Art. 2, $\S 1^{\mathrm{o}}$, a docência é compreendida como:

ação educativa e como processo pedagógico intencional e metódico, envolvendo conhecimentos específicos, interdisciplinares e pedagógicos, conceitos, princípios e objetivos da formação que se desenvolvem na construção e apropriação dos valores éticos, linguísticos, estéticos e políticos do conhecimento inerentes à sólida formação científica e cultural do ensinar/aprender, à socialização e construção de 
conhecimentos e sua inovação, em diálogo constante entre diferentes visões de mundo.

Como se constata, o CNE/2015 apresenta a profissão de professor atrelada a um processo pedagógico intencional e teórico-metodológico, envolvendo conhecimentos específicos que legitimam a especificidade do trabalho docente. Entende-se que as diretrizes, ao colocarem o trabalho docente numa instância intencionalizada, partem da prerrogativa de que o professor reflete e planeja antes de agir. Nesse discurso, não se pode conceber os professores como operadores ou meros executores de técnicas ou receituários.

Nessa direção, para Giroux (1997), os professores como intelectuais articulam a conceitualização, planejamento e organização curricular com os processos de implementação e execução. Nessa visão, o professor, na prática, assume responsabilidades, levanta questionamentos acerca do que ensina e para que ensina, em vista de uma escola de qualidade, comprometida com o desenvolvimento de uma sociedade cidadã, justa e democrática. Especificamente, sobre a importância e qualidade dos professores de educação para atuação com crianças, Sanches (2003, p. 57) afirma que:

Há clara evidência de que a qualidade do professor é um determinante central na qualidade e eficiência dos programas de Educação Infantil [...] se quisermos melhorar a qualidade da educação de crianças pequenas devemos nos preocupar com a qualidade de seus professores. Em toda Europa os países estão reconhecendo isso e tomando medidas para melhorar os cursos de formação de professor de Educação Infantil.

Nesse contexto, a formação de professores para Educação Infantil também não deve acontecer com foco na teoria sem a prática e na prática sem a teoria. Por isso, a formação inicial deve ser, sobretudo, a contínua, na perspectiva crítico-reflexiva, que parte da aproximação entre os discursos gerais, da prática e teóricos, na tentativa de levantar possíveis interpretações acerca da educação oferecida e daquela a oferecer.

No entender de Magalhães (2004), busca-se, especialmente, nas escolas, abrir um espaço em que professores, alunos, gestores, coordenadores e também pesquisadores falem sobre suas escolhas teórico-práticas, para se conscientizarem dos próprios discursos e das ações e relações nas salas de aula, para assim poderem perceber e entender a contradição do dizer e das escolhas feitas. 


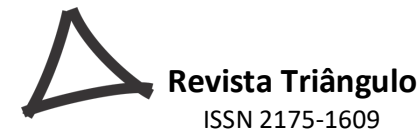

A perspectiva crítico-reflexiva de formação de professores de Educação Infantil que iluminou os estudos procurou superar a visão técnica, estritamente focada no contexto da sala de aula ou ainda estritamente focada na instituição escolar, ao incluir, além das discussões prático-teórica, a esfera social no papel do professor como agente político e empoderado (FREIRE, 2011; ENGESTRÖM, 2013).

Está, portanto, respaldada também na perspectiva crítico-reflexiva (GIROUX, 1997; PÉREZ GÓMEZ, 1998; MAGALHÃES, 2004, 2014) para a constituição de um profissional que age intencionalmente e politicamente na colaboração de alunos agentes (LIBERALI, et al, 2015). Dito isso, é necessário ressaltar que a reflexão que se defende está sustentada numa compreensão de prática social conjunta, que concebe a escola de Educação Infantil como “comunidade de aprendizagem” (MAGALHÃES, Projeto CNPq, 2015-2018) nas quais os professores - gestora, coordenadora, pesquisadora - apoiam-se e, mutuamente, suporte criando condições e possibilidades de mudanças e transformações no contexto micro e macrossocial.

Em síntese, ao reconhecer a essencialidade do papel do professor - nas tomadas de decisões, escolhas e mobilização das práticas na escola - busca-se pensar o currículo por uma via de formação crítica apoiada no inter-relacionamento de vozes, compreensões e realidades dos participantes que estão situados em um dado contexto social. Portanto, uma formação no campo da Educação Infantil que fuja dos modelos clássicos, ao construir, em conjunto, modos de agir e enfoque teórico-práticos capazes de favorecer mudanças na realidade da escola e em todos os sujeitos envolvidos.

\section{METODOLOGIA DA PESQUISA}

A Pesquisa Crítica de Colaboração - doravante PCCol - é apresentada por Magalhães (2014) como uma proposta ativista e intencionalmente focada na organização de um espaço crítico, em que pessoas possam agir, falar e ouvir uns aos outros para revelar sentidos, aprofundar teorias, discutir contradições de sentidos e significados historicamente produzidos.

Esse modelo de pesquisa-formação-intervenção, apoiado nas discussões da Teoria da Atividade sócio-histórico-cultural, tem como fundamento os conceitos de colaboração e contradição. O conceito de colaboração, em Magalhães (2014), inspira-se nos aportes filosóficos espinosanos e marxistas ao relacionar este conceito à ideia de homem livre criador e produtor de encontros felizes na constituição de sua existência sócio-histórico-cultural. Já o conceito de contradição, para a referida autora, tem suas bases nas discussões acerca do 
movimento inerente aos fenômenos presente na lógica dialética marxista, e nas discussões de Engeström (2013), especialmente, quando se refere à organização de contextos focados no confronto, contestação e ressignificação de sentidos e produção compartilhada de significado.

Um importante princípio da PCCol está na perspectiva crítica, que se refere a uma visão de formação social marcada pela resistência a imposição de conhecimentos e ideias inquestionáveis, cuja luta incide pela emancipação, justiça e democracia.

Ao resistir e questionar o socialmente dado, busca-se compreender aspectos ideológicos e políticos que permeiam as relações na escola em prol de um agir coletivo focado na transformação das "situações-limites” em “inédito viável” (FREIRE, 2011, p.130).

Assim, durante as atividades de formação com as professoras e gestora, na escola MBC, foi possível viver, a colaboração que se materializou no processo dinâmico intencional e interacional das relações coletivas, de refletir criticamente, mediatizadas pela linguagem, focada na reconstrução e reorganização de práticas e saberes (NININ, 2013).

Nesse contexto, todos os participantes da investigação formaram-se profissionalmente e construíram conhecimentos que emergiram da visão de trabalho coletivo. As professoras de Educação Infantil no processo de pesquisa-formação-intervenção não foram reconhecidos como aqueles sobre os quais apenas deles se escreve, mas, acima de tudo, com os quais se estuda e se reflete, pois, a produção de conhecimento "[...] envolve mais do que interação entre os participantes. Envolve colaboração, suporte e assistência na reflexão e reinterpretação coletiva da ação" (MAGALHÃES, 2004, p. 52).

A colaboração na escola foi valorizada ao propor momento de discussão entre pares, ao considerar que todos da escola têm vez e voz. Nesse contexto aberto a emitir enunciados, todos puderam evidenciar tensões produzidas nos conflitos inter e intrapsicológicos, processos esses responsáveis por transformar o pensar e o agir das pessoas.

A formação na escola internacionalmente criada para compartilhamento de significados mediado pela linguagem da argumentação - gerou ainda a possibilidade de se pensar, com o outro, problemas de interesse individuais, mas, também, de interesses do grupo, uma vez que o individual reflete, diretamente, no resultado coletivo. Assim, a colaboração existiu quando o objetivo da ação, o motivo, tornou-se relevante para todos os envolvidos na situação.

No desenvolvimento da pesquisa-formação-intervenção foram utilizados como procedimentos de produção de dados: encontros de formação, aulas, planejamentos e projeto 
de ensino-aprendizagem com base em Atividades Sociais. As ferramentas: equipamentos tecnológicos que subsidiaram as transcrições de áudio e captura de imagens

Neste texto, o foco é dado aos encontros de formação. No caso, entende-se por Encontros de Formação, os momentos em que houve reunião na escola lócus de investigação com o grupo de participantes da pesquisa para se discutir e estudar assuntos previamente selecionados a partir de necessidades externadas pelo grupo.

Os assuntos para discussões iniciais surgiram a partir de observações da prática docente na escola feita por esta pesquisadora quando ainda era professora da escola (período 2012 a 2014). As observações como professora da escola materializaram-se em uma proposta de curso ministrado já na condição de professora vinculada a Universidade Estadual do Piaú-UESPI.

A discussão acerca da linguagem e do currículo sugerida à escola no curso revelou-se temática interessante, especialmente, para o grupo da escola, que externou desejo e necessidade de buscar e encontrar sua identidade como instituição de Educação Infantil.

O curso que havia sido programado para concluir no primeiro semestre de 2015, continuou até 2016. Porém, não mais vinculado ao projeto de extensão universitária da UESPI, pois o foco na organização da linguagem das professoras, como previa o projeto inicial, foi substituído por um estudo voltado exclusivamente para uma formação que pudesse colaborar com a revitalização do currículo da escola.

A formação passou a estar vinculada ao interesse do grupo em fortalecer-se práticoteoricamente a respeito do trabalho que se faz e se deseja fazer na escola mediante uma revisita ao currículo vigente.

Estiveram envolvidas durante a pesquisa-formação-intervenção cerca de treze pessoas: a gestora eleita/concursada da rede municipal da cidade de Parnaíba-PI, duas professoras concursadas, quatro professoras celetistas/contratadas pela rede por seleção simplificada, três bolsistas/universitárias contratadas pela rede como auxiliares de sala, uma aluna universitária que cumpria seu estágio obrigatório da disciplina Estágio Supervisionado da UESPI, um pesquisador/colaborador e, esta pesquisadora responsável pelos estudos. Dentre as pessoas envolvidas, optou-se por definir como professoras focais: Rô, Lu, Paty, Ely e a pesquisadora: Fá. Houve sete encontros de formação realizados entre o período de 2015-2016.

Neste texto, destacam-se o sexto e o sétimo encontro. 


\section{ANÁLISE DOS DADOS E RESULTADOS}

Os dados da investigação selecionados para serem apresentados, neste artigo, foram produzidos em um projeto de pesquisa-formação-intervenção na Escola Municipal MBC envolvendo pesquisadora, gestora, professoras e crianças entre três e cinco anos de idade, realizado no primeiro semestre de 2016 com autorização do Parecer CEP/PUC n ${ }^{\circ}$ 1.398.245.

Seja o discurso na ordem pragmática ou epistêmica, Ninin (2016) enfatiza, que todos os discursos são argumentativos e que, por assim entender, as ações discursivas argumentativas em contexto de formação contínua na escola merecem contemplar formas de participação em que todos os sujeitos da interação dialógica se sintam estimulados, envolvidos e dispostos a apresentar seus posicionamentos, discordâncias, justificar pontos de vistas, negociar divergências, desencadeando movimentos dialógicos que provoquem expansão.

Por essa razão, na formação em contexto escolar, considerou a linguagem em seus aspectos enunciativos, linguísticos, discursivos (LIBERALI, 2013). Sobre cada um dos aspectos da linguagem argumentativa, Liberali (2013) discute que é característica da categoria enunciativa focalizar o contexto em que o fenômeno estudado acontece. Dessa forma, a análise desenvolvida da materialidade esteve atenta ao situar o leitor para: de onde se fala, quando se fala, quem fala, porque se fala e do que se fala.

Quanto à categoria discursiva, iluminada por autores como Leitão (2011), Pontecorvo (2005), e outros, Liberali (2013), propõem quatro aspectos essenciais. São eles: o plano organizacional, organização temática, foco sequencial, articulação de ideias. $\mathrm{Na}$ análise dos dados, o foco das características discursivas esteve na articulação entre as ideias, focado nos modos como as vozes dos participantes se entrelaçaram no discurso e os efeitos de sentidos ou impressões causadas.

As características linguísticas enfocadas, nas análises, para exemplificar: os mecanismos conversacionais (expressos pelo uso de interrogação, pausa, elipse, complementação, permeabilidade, exclamação); os mecanismos lexicais (refere-se aos léxicos que se tornam foco do enunciado, os vocábulos próprios, o gênero dos nomes, os números, palavras marcadas por suas teorias ou conceitos e expressões escolares); os mecanismos de coesão verbal (relacionados ao verbos e seus determinantes na instituição do texto, caracterizados por temporalidade, aspectualidade e os tipos de processo que imprimem); os mecanismos de coesão nominal (designam as conexões de dependência entre os argumentos das propriedades referenciais causando efeito de estabilidade e de continuidade) e $o s$ 
mecanismos de proferição (os paraverbais relativos ao canal auditivo: silêncio, entonação, pausas, intensidade, ritmo da fala ou altura da voz).

Diante do exposto, apresentam-se três excertos que evidenciam, pela linguagem, as transformações que a formação propiciou a prática docente das professoras de Educação Infantil.

Os excertos, que aparecem nesta seção, foram extraídos de dois encontros de formação, o $6^{\circ}$ e $7^{\circ}$.

O $6^{\circ}$ encontro teve como tema: O Lugar do brincar na escola e aconteceu no dia 07.05.2016 das $8 \mathrm{~h}$ às $9 \mathrm{~h} 30 \mathrm{~min}$ da manhã na própria escola. Estavam presentes, a gestora Rô, as professoras Lu, Paty, a professora celetista Drica, as estagiárias Naiane, Iza e a pesquisadora Fá. No período desse encontro, já havia iniciado o desenvolvimento das primeiras aulas do Projeto Ir à Lanchonete.

O $7^{\circ}$ encontro foi realizado no final do ano letivo de $2016(07.12 .2016)$ com o tema: $A$ tradição do brincar: antes e hoje. No encontro estavam presentes as professoras Lu, Paty, Lid, a gestora Rô, a pesquisadora Fá e o colaborador Afrânio.

No encontro, a pesquisadora apresentou excertos de transcrições, em slides dos primeiros encontros de 2015, que tratavam sobre o brincar na escola antes dos projetos por AS e, depois, apresentou algumas fotografias do projeto "Ir à Lanchonete", especialmente, aquelas que tratavam das performances em que estavam presentes as crianças e as professoras nas cenas, brincando.

No encontro de formação $6^{\circ}$, a pesquisadora Fá levantou para o grupo a discussão sobre como o brincar vinha acontecendo na escola e a prof. a Paty manifestou-se dizendo:

Excerto 01: de 07.05.2016

$\begin{array}{lll}\begin{array}{l}\text { Turno } \\ 78^{1}\end{array} & \begin{array}{l}\text { Quem } \\ \text { Paty }\end{array} & \begin{array}{l}\text { É assim, eu acho assim, agora sim, agora sim tem sido pensado o brincar. Na minha } \\ \text { opinião! Eu acho que antes nós tentávamos, mas não tanto assim com a brincadeira. }\end{array} \\ 79^{1} & \text { Fá } & \text { Sim, explique melhor, diga assim com outras palavras o que você acabou de dizer. } \\ 80^{2} & \text { Paty } & \text { Sim (Rsss). Assim } \\ 81^{1} & \text { Rô } & \text { Fale por ti, fale sobre o que você acha, não sobre o que o outro acha. Fale por ti. } \\ 82^{3} & \text { Paty } & \text { pois é, por mim. } \\ 83^{2} & \text { Fá } & \text { Sim, Fale o que você pensa. } \\ 84^{4} & \text { Paty } & \begin{array}{l}\text { Pois é, da parte lúdica e o planejamento dessas atividades. Com relação às atividades } \\ \text { lúdicas, né! Existe a brincadeira no recreio, no cantinho, mas na sala mesmo, não. Não }\end{array} \\ & & \begin{array}{l}\text { existia. Pelo menos na minha sala o planejamento era mais no sentido de ensinar. } \\ \text { Agora, agora sim. Agora. Eu, eu estou aprendendo a levar a brincadeira para sala }\end{array}\end{array}$


de aula. Agora eu entendo que quando a gente leva a brincadeira, a gente contribui mais para o desenvolvimento da criança, ela aprende muito mais.

\section{Legenda}

_ Intensidade na voz

No excerto 1, a prof. a Paty, ao usar o pronome na primeira pessoa (eu), marcou linguisticamente sua atuação na produção de um discurso sobre o brincar na escola.

A propósito do assunto, colocou que, na sua opinião, o brincar não vinha sendo pensado (planejado), de fato, na instituição. Também, assinalou com a repetição do advérbio de tempo presente (agora) que a prática, hoje em dia, ganhou atenção em seu trabalho. Ao falar da prática do momento presente, do agora, a professora, de certa foram, nega o passado e, para esclarecimento de seu ponto vista, destaca que, antes [do projeto por AS], o brincar acontecia restrito, por exemplo, aos momentos de recreio ou no cantinho de fantasia, como mostra o turno 84.

No enunciado, a professora destaca ainda sua nova compreensão sobre o brincar. A necessidade de ter que planejar as brincadeiras no projeto, organizar cenários em sala de aula ou fora dela, em que crianças e professoras pudessem brincar levou a prof. ${ }^{\text {a }}$ Paty a rever suas posições e entendimentos sobre a contribuição do brincar às crianças na Educação Infantil.

No excerto, acima, prof. a Paty revela que antes [do projeto por AS], nos planejamentos, o seu foco estava em uma prática para ensinar e não num planejamento que pudesse pensar sobre o quê? Para quê? Como as crianças aprendem?

A escolha lexical da expressão, no sentido de ensinar, por parte da locutora trouxe em seu discurso a ideia de desaprovação de seu próprio modelo de educação voltado para "[...] "encher" os educandos de conteúdo", sobre o qual Freire (2011) explica serem na maioria dos casos, "retalhos da realidade desconectados da totalidade em que se engendram e em cuja visão ganhariam significação (FREIRE, 2011, p. 79-80).

Nesse caso, como apresentado por Paty, e já discutido em outros recortes, o trabalho na escola estava voltado para o sentido de ensinar, isto é, para o sentido de "encher" as crianças de conteúdo na sala de aula, podendo-se compreender que a prática da professora tinha uma base curricular escolarizante (KUHLMANN JR, 2007).

Por outro lado, o uso de verbos no passado na descrição do modelo do brincar e o uso de mecanismos de proferição paraverbais como, intensidade de voz em palavras ( $\underline{\text { Agora/Eu}}$, a repetição de "agora" indicaram que a prática do brincar da professora ganhou uma nova direção, 
mostrando reconhecimento de que oportunizando brincadeiras, na sala de aula, as crianças se desenvolvem e aprendem.

Os enunciados, assim, sugerem que o pensamento da professora sobre o brincar se reformulou e se aproximou das concepções defendidas dentro do quadro teórico vigotskiano. Mas, especificamente, revelam que a prática, o fazer cotidiano, o modo de brincar da prof. ${ }^{\text {a }}$ Paty com as crianças se transformou.

No excerto seguinte, extraído do encontro de formação $7^{\circ}$, a pesquisadora Fá, partindo dos dados expostos nos slides que apresentava, questionou se o brincar, na escola, continuava tendo as mesmas características que tinha antes do desenvolvimento do projeto "Ir à lanchonete" ou se havia acontecido mudanças. Sobre o assunto destaca:

Excerto 2: 07.12.2016

Turno Quem

Fala

145 $\quad$ Fá $\quad$ E o quê que mudou? Mudou/do brincar antes pra esse brincar agora!

$146^{1}$ Paty Mudou a participação também, né?! o direcionamento\#

$147^{2} \quad$ Fá Mas de quem?

$148^{2}$ Paty Meu. A minha participação. Eu participei mais. E, o direcionamento, porque como já foi falado pela Lu, na brincadeira, eles/ cada um teve o seu papel distribuindo. Nesse momento aí [referindo-se a foto no slide], eu estava sendo garçonete, mas teve outros momentos que eles é que eram. Alguém era o garçom, o outro era o caixa e outro ficava sendo atendente e eu era a cliente. Então, teve a distribuição de papéis /

Legenda

/ - pausa curta

\# - interrupções na fala, feita por um segundo participante

Nesse dado da pesquisa, prof. ${ }^{\text {a }}$ Paty afirmou que a mudança acerca do brincar aconteceu, no que se refere à sua participação e ao modo como a relação dos sujeitos na brincadeira aconteciam.

Na composição do discurso, a professora emprega pronomes possessivos ("minha") e pessoais ("eu") que declaram seu efetivo envolvimento e o das crianças durante a brincadeira, intensificado pelo uso do advérbio "mais". O papel assumido da professora, no brincar, indica novo modo de agir com as crianças nos momentos de brincadeira na escola. Dessa forma, a mudança no jeito de brincar sublinhou a efetiva participação de todos os sujeitos que compõem a sala de aula mediante distribuição clara de troca papéis sociais, expresso pela fala "eu estava sendo" versus "eles é que eram" 
Pode-se constatar que a divisão dos papéis, nas performances da atividade social "Ir à lanchonete", foi central para a produção de um novo modo de viver o brincar e conceber o currículo da escola.

No quadro da teoria da atividade, os papéis que os sujeitos assumem ou assumirão cumpre função decisiva na produção e dinâmica das atividades humana. É no aprender a viver os papéis sociais que nos tornarmos expectadores da vida conferida ou agente que luta e a transforma. Além do mais, a divisão dos papéis oferece oportunidade de as crianças experimentarem diversas posições e desenvolvimento.

Como defende Martins (2006), o jogo com papéis sociais é capaz tanto de proporcionar às crianças níveis de desenvolvimento tão complexos da percepção, como ainda é capaz de desenvolver níveis mais elevados de compreensão do meio, especialmente, tornar mais acuradas as compreensões sobre as relações sociais de seu contexto.

Assumir um papel social na brincadeira significa que as crianças gostam de brincar e representar o homem. Brincar sem haver essa representação não há brincadeira de papéis sociais, porque o motivo principal para o jogo infantil é o próprio papel que assumem (ELKONIN, 2009). A relevância desse modo de brincar consiste no fato de que, no desenvolvimento da brincadeira, o foco inicial da criança é o papel que assume, mas, depois, desloca-se para a maneira como ela compreende o seu próprio papel no meio social (ELKONIN, 2009).

De acordo com o excerto 2, brincar com a Atividade Social "Ir à lanchonete" gerou na turma da prof. ${ }^{a}$ Paty a necessidade da imitação, da imaginação criativa, mas gerou principalmente, um processo único de interpretação de um dado papel social. Gerou um cenário do tornar-se. (NEWMAN; HOLZMAN, 2014).

É interessante notar que a nova organização dos cenários e nova característica nas relações dos sujeitos ao brincar no projeto conduziram professoras e crianças a um novo modo de viver as situações da vida cotidiana, como mostra o excerto extraído do encontro de formação $7^{\circ}$ abaixo:

No excerto a seguir, retirado do encontro de formação $7^{\circ}$, a gestora emite sua opinião sobre as modificações percebidas:

Excerto 3: 07.12.2016

Turno Quem fala

391 Rô Eu não sei/ Mas talvez por estar de fora, o olhar de fora, eu vejo. Eu vejo a mudança de vocês. Eu sei que a $\mathrm{Lu}$ acha difícil, mas eu vejo a mudança na Lu, na Paty, até na 


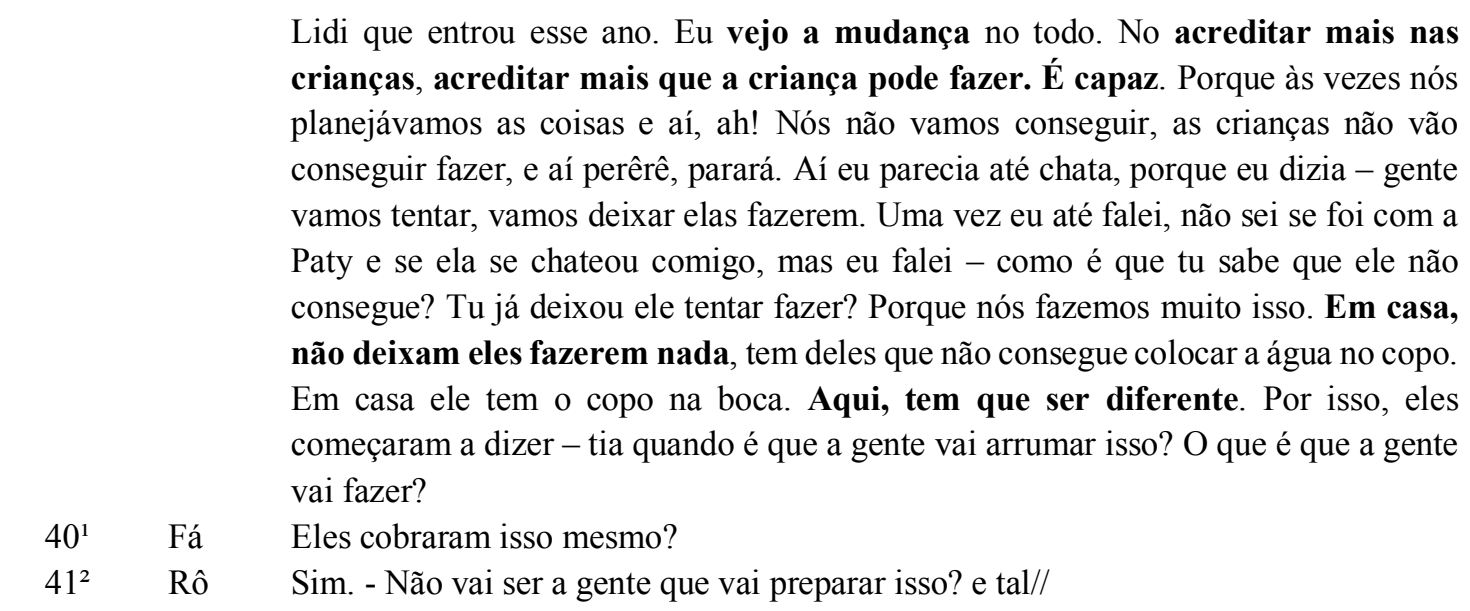

Legenda:

// - pausa longa

No excerto, a discussão central era sobre as possíveis mudanças no currículo da escola após o projeto. A prof. ${ }^{a}$ Lu, na discussão, havia dito que uma mudança radical do currículo necessitaria de tempo pois, ora se via revendo sua prática de brincar com as crianças ora se via negligenciando o brincar do mesmo jeito como antes do projeto e essa dualidade a angustiava.

Depois da fala da professora Lu, a gestora Rô pronuncia-se mais positivamente sobre as mudanças provocadas pelo projeto à equipe. Linguisticamente, isso pode ser percebido pela atitude comunicativa de envolvimento, certeza e de compromisso que o uso dos verbos pela gestora, no modo indicativo, sugere na exposição de seu ponto de vista: "Eu vejo a mudança de vocês", "Eu vejo a mudança no todo".

Apresentando exemplos e esclarecimentos sobre seu ponto de vista, Rô coloca que, depois do projeto da lanchonete, aconteceram, nitidamente, mudanças no modo de agir de todas as três professoras da escola, inclusive no modo de agir da prof. ${ }^{a}$ Lu que se mostrava na ocasião aflita por desejar uma transformação total.

Segundo a gestora, a transformação cabal do currículo produzida com a experiência do projeto com a atividade social "Ir à lanchonete" foi quanto à mudança de perspectiva acerca das crianças.

Antes do projeto, as professoras subestimavam a capacidade dos alunos. Hoje em dia, parecem acreditar muito mais. Tal mudança é central para vivência de uma proposta curricular para Educação Infantil que acredite na potencialidade e assegure à criança oportunidade para criar, expressar-se com suas múltiplas linguagens, desenvolver a imaginação e agência. 
Acreditar nas crianças é central para favorecer experiências que a levem pensar e compreender o tipo de homem e sociedade que temos e pretendemos criar.

\section{CONSIDERAÇÕES FINAIS}

Este artigo apresentou recortes de uma pesquisa de doutorado que discute, centralmente, a reorganização do currículo de uma escola de Educação Infantil a partir da implementação de um projeto de intervenção organizado por Atividades Sociais (LIBERALI, 2009). Tal pesquisa promoveu um intenso processo de formação contínua capaz de provocar em um grupo de professores, juntamente com a gestão, a necessidade de e o desejo de revitalizar as práticas desenvolvidas na escola.

A formação, no caso, esteve focada nas discussões do currículo da escola, especialmente, no que tange a compreensão do brincar no contexto da educação infantil. No processo formativo da pesquisa crítica de colaboração foi discutido sobre o modelo de brincar que vinha sendo realizado e como os estudos no quadro teórico de base sócio-histórico-cultural, sugere. Ao realizar tais estudos as professoras passam a agir diferente de como vinham agindo transformando a realidade do brincar na escola.

Por meio da formação favorecida pela pesquisa o brincar, intencional, ganhou mais espaço e relevância para o trabalho das professoras. Isto é, fez o brincar ganhar visibilidade, importância e necessidade no contexto da atividade com as crianças e professoras.

Depois dos novos modos de pensar e agir de professoras e crianças durante a implementação do projeto, novos modos de pensar e agir foram revelados no cotidiano da instituição, a exemplo: professoras escutam mais as crianças, organizam cenários de brincadeiras/performances para diversão com elas; as crianças, também assumem papéis na organização dos cenários para as brincadeiras e em outras atividades coletiva da escola. Atualmente, na escola, as organizações coletivas com objetivos comuns são privilegiadas em detrimentos de organizações individualizadas.

Os estudos subsidiados pela pesquisa-formação-intervenção é um exemplo de bons resultados advindos de um processo sistemático de formação na escola. Os indícios revelados nos excertos comprovam que a escola passou a viver novos modos de brincar por crianças e professores. Consequentemente, é possível inferir que os modelos de formação quando acontecem partindo das necessidades e desejos das demandas da escola tende a gerar efetivas transformações educativas. 


\section{Notas}

${ }^{1}$ Entende-se por Atividades Sociais uma alternativa de organização curricular que, ao se pautar em princípios da Teoria da Atividade Sócio-Histórico-Cultural, oportuniza a comunidade escolar vivências de atividades sócio-culturais diretamente vinculadas à "vida que se vive" (MARX e ENGELS 2006, 26), pelo viés do desenvolvimento da atividade de brincar. Ao viver esses momentos em forma de brincadeiras, os sujeitos assumem papéis sociais que ultrapassam a esfera escolar, provocando repensar ou criar novas formas de sentir e agir nos diferentes contextos da sociedade.

\section{REFERÊNCIAS}

ADORNO, T. W. Notas marginais sobre teoria e práxis. In: ADORNO, T. W. Palavras e sinais: modelos críticos 2. ed. Petrópolis- RJ: Vozes, 1995. p.15-25.

BRASIL. Conselho Nacional de Educação. Conselho Pleno. Parecer no 2/2015. Diretrizes Curriculares Nacionais para a Formação Inicial e Continuada dos Profissionais do Magistério da Educação Básica. Brasília, DF: CNE, 2015

ELKONIN, D. B. Psicologia do Jogo. São Paulo: Martins Fontes, 2009.

ENGESTRÖM, Y. Teoria da Atividade Histórico-Cultural e suas contribuições à Educação, Saúde e comunicação: entrevista com Monica Lemos, Marcos Antonio Pereira-Queirol, Idelberto Munis de Almeida. Interface: Comunicação Saúde e educação, v. 17, n. 46, p. 715727, jul/set. 2013.

FREIRE, P. Pedagogia do Oprimido. 50. ed. Rio de Janeiro: Paz e Terra, 2011.

GIROUX, A. H. Os professores como intelectuais: rumo a uma pedagogia crítica da aprendizagem. Porto Alegre: Artes Médicas, 1997.

KISHIMOTO, T. M. Currículo de Educação Infantil: creches e pré-escolas. Significado do termo currículo, currículo de Educação Infantil: critérios de qualidade e instrumentos de implementação. Texto encomendado pela coordenação geral de Educação infantil do MEC, 1994 (mimeo).

KRAMER, S. Propostas pedagógicas ou curriculares de Educação Infantil: para retomar o debate. Revista Pró-posições. v. 13, n. 2, mai/ago. 2002. Disponível em:

http://www.proposicoes.fe.unicamp.br/proposicoes/edicoes/texto373.html. Acesso em: 30 jan. 2017.

KUHLMANN JR. M. Infância e Educação Infantil: uma abordagem histórica. Porto Alegre-RS: Mediação, 2007.

LEITÃO, S.; LEITE. L. B-. Argumentação na linguagem infantil: algumas abordagens. In: DEL RÉ, A. (Org.). Aquisição da linguagem: uma abordagem psicolinguística. São Paulo: Contexto: 2010. p. 45-84. 
LIBERALI, F.C. Atividade social nas aulas de Língua Estrangeira. São Paulo: Moderna, 2009.

LIBERALI, F.C. Argumentação em contexto escolar. Campinas-SP: Pontes, 2013.

LIBERALI, F. C. et al. Projeto DIGIT-M-BRASIL: uma proposta de desencapsulação da aprendizagem escolar por meio dos multiletramentos. Revista Prolínguas. v. 10, n. 3, Nov/Dez 2015.

MAGALHÃES, M.C.C. Escolhas teórico-metodológicas em pesquisas com formação de professores: as relações colaborativos-críticas na constituição de educadores. In: MATEUS, E.; OLIVEIRA, N.B. (Org.). Estudos críticos de linguagem e formação de professores de línguas: contribuições teórico-metodológicas. Campinas, SP: Pontes, 2014. p. 17-47.

MAGALHÃES, M.C.C. A linguagem na formação de professores como profissionais reflexivos e crítico. In: MAGALHÃES, M.C.C. (Orgs). A formação do professor como um profissional crítico: linguagem e reflexão. Campinas-SP: Mercado de Letras, 2004. p. 5985.

MAGALHÃES. M.C.C. A pesquisa crítica de colaboração: construindo comunidades para aprendizagem e desenvolvimento, em projeto de formação de educadores. Projeto de pesquisa, 2015.

NEWMAN. F; HOLZMAN. L. Lev Vygotsky: cientista revolucionário. São Paulo: Loyola, 2014.

NININ, M. O. G. Da pergunta como ato monológico avaliativo à pergunta como espaço para expansão dialógica: uma investigação à luz da Linguística Aplicada sobre modos de perguntar. São Carlos-SP: Pedro \& João, 2013.

NININ, M. O. G. Padrões de colaboração e argumentação: uma perspectiva crítica para a análise do desenvolvimento de educadores. In: LIBERALI, F.C. et all (Orgs.). Argumentação em contexto escolar: relatos de pesquisa. Campinas: Pontes Editores, 2016. p.175-204.

OLIVEIRA, Z. M. R. O trabalho do professor na Educação Infantil. 2. ed. São Paulo: Biruta, 2014.

PONTECORVO, C. Interação social e construção do conhecimento: confronto de paradigmas e perspectivas de pesquisa. In PONTECORVO, C. Discutindo se aprende: interação social, conhecimento e escola. Porto Alegre: Artmed, 2005. p. 45-61.

RAUPP, M. D. Concepções de formação das professoras de Educação Infantil na produção científica brasileira. In: VAZ, A. F; MONN, C. M. Educação Infantil e sociedade: questões contemporâneas. Nova Harmonia: São Paulo, 2012. p. 139-156.

RECH, H. L. Apontamentos sobre o conceito de práxis, indústria cultural, ideologia e educação em Theodor Adorno. Disponível em:

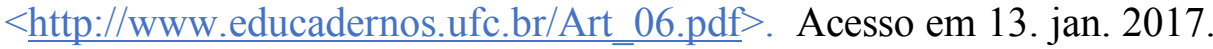


SACRISTÁN, Gimeno; PEREZ GÓMEZ, A. I. Compreender e transformar o ensino. 4. ed. São Paulo: Artmed, 1998. p. 353-379.

SANCHES, E. C. Creche: realidade e ambigüidades. Petrópolis, RJ: Vozes, 2003.

VIGOTSKI, L. S. A formação social da mente. 7. ed. São Paulo: Martins Fontes, 2007. 